\title{
Pediatric pleural empyema: one of the management challenges in children of Democratic Republic of Congo
}

\author{
Kibwe Alphonse Simbi, 1,2 Valentin Kazadi,2 Louis-Marie Aissi, 2 François Mbahewaka Katsuva, ${ }^{3}$ \\ Numbi Oscar Luboya, ${ }^{4}$ Léon Tshilolo, ${ }^{2}$ Vincenzo Zanardo 1 \\ ${ }^{1}$ Abano Terme General Hospital, Abano Terme (PD), Italy; ${ }^{2}$ Centre Hospitalier Monkole, Kinshasa; ${ }^{3}$ University of \\ Graben, Butembo; ${ }^{4}$ Department of Paediatrics, University of Lubumbashi, Lubumbashi, Democratic Republic of Congo
}

\begin{abstract}
Empyema is a serious complication characterized by purulent exudate and bacteria in the pleural space, which may progress to necrosis, cavitations or fistulas in the thoracic cavity. It remains a major challenge throughout low-income countries. Objectives were to emphasize the role of basic medical and radiologic approach and to resolve a severe lung complication when facilities are inadequate. A five-year-old female was referred with distress respiratory to the Emergency Unit of Monkole, a large public-private missionary hospital in Kinshasa, Congo. Chest X-ray showed a massive empyema that was resolved by immediate drainage and antibiotiocs. Results were rapid improvement and discharge after 3 weeks. A classic medical and imaging approach is a winning
\end{abstract}

Correspondence: Simbi Kibwe Alphonse, Abano Terme General Hospital, Piazza C. Colombo 1, 35031 Abano Terme (PD), Italy. Tel: +39.0498221274 - Fax: $+39.8601651 / 8611136$

E-mail: simbialphonse@libero.it

Key words: Pleural empyema; Management; Challenge; Paediatric; Low income country.

Aknowledgements: the authors would like to thank Nicky Coote and Ian Balfour - Lynn for their welcome support in giving access to their papers and as valuable contributions in preparing this case report.

Conflict of interest: the authors declare no potential conflict of interest.

Contributions: SKA and TL gave substantial contributions to the conception and design, acquisition of data, drafting of the case; AL-M followed up the patient and took part of the drainage performed by $\mathrm{KV} ; \mathrm{ZV}$, LO and MF have contributed to the revision. All the authors gave substantial contributions to the critical revision for important intellectual content, and final approval of the version to be published. The authors did not receive any grant from government or institution for this case report.

Received for publication: 7 February 2016

Revision received: 30 March 2017

Accepted for publication: 3 April 2017.

This work is licensed under a Creative Commons Attribution

NonCommercial 4.0 License (CC BY-NC 4.0).

(C) Copyright K.A. Simbi et al., 2017

Licensee PAGEPress, Italy

La Pediatria Medica e Chirurgica 2017; 39:131

doi:10.4081/pmc.2017.131 return in low-income countries. According to the British Thoracic Society guidelines, pleural effusion with compromising respiratory function can be managed by drainage and antibiotics.

\section{Introduction}

Pleural empyema is a collection of purulent exudate between the lungs and the chest wall. Empyema is not rare in our practice. ${ }^{1-3}$ Once a massive empyema is diagnosed by chest radiology, closed chest drainage proves a very effective challenge to pediatric management in our referral district hospital where facilities are lacking. The role of thoracic ultrasound in guiding investigation and drainage of empyema is clear. Prompt treatment with appropriate systemic antibiotics and chest tube drainage are the key to success. ${ }^{4-6}$ We aim to describe a case report and review literature of pediatric empyema management emphasizing the role of a standard medical approach, when and where diagnostic instrumental and bacteriological tools are inadequate or absent.

\section{Case Report}

A five-year-old, female, was admitted to the Emergency Unit of Monkole, a public private missionary hospital in Kinshasa, Democratic Republic of Congo (DRC) with respiratory distress and a sepsis complaint, having had an antecedent of infective respiratory disease, antibiotics and quinine intake in the last two weeks before admission. A detailed family history revealed that both parents of the child were Congolese with no family history of sickle-cell disease. An initial investigation showed on physical examination, a wide spectrum of clinical involvement including critical illness, shortness of breath, dullness to percussion, reduced breath sounds on the left field and persistent fever. Blood testing showed raised white blood cell count $\left(32,000 / \mathrm{mm}^{3}\right)$, altered inflammatory markers (the erythrocyte sedimentation rate, was at $101 \mathrm{~mm} / \mathrm{h}$ ). A chest x-ray showed an homogenous increase in opacity over the whole left lung field with blunting of the costophrenic angle and deviation of the mediastinium on the right side (Figure 1).

The presence of frankly purulent exudate on pleural aspiration with a single needle indicated the need for prompt chest tube drainage which was performed immediately without radiological or echographic guidance by an adequately trained physician in $4^{\text {th- }}$ $5^{\text {th }}$ intercostal midaxillary, based on standard medical approach of the chest, in local anaesthesia with Emla ${ }^{\circledR}$ (Lidocaine and prilo- 
caine). Biochemical sampling cultures of the pleural fluid and Gram stain were negative. Conversely the Rivalta test was positive. Tuberculosis, Aids and malignancy were also considered and excluded in the absence of pleural lymphocitosis, with granulocitosis. Sputum was not available. Analgesia (acetaminophen 10-15 $\mathrm{mg} / \mathrm{kg}$ ) was important to keep the child comfortable, particularly in the presence of lasting tube chest drain. Oxygen $(2 \mathrm{~L} / \mathrm{min}$ ) by nasal cannulae and intravenous antibiotics (ampicillin $50 \mathrm{mg} / \mathrm{kg} \times 2 /$ day, gentamicin $5 \mathrm{mg} / \mathrm{kg} \times 1 /$ day and ceftriaxone $70 \mathrm{mg} / \mathrm{kg} \times 1 /$ day) were given for two weeks. A pre discharge decreased white blood cells count from 32,000 to $6700 / \mathrm{mm}^{3}$ was reassuring that the infection was being treated appropriately. An oral antibiotic (amoxicillin $50 \mathrm{mg} / \mathrm{kg}$ ) continued for 4 weeks following discharge. Clinical and Rx (Figure 2) follow up was good at 3 months without complications.

\section{Discussion}

Despite being recognized for over two millennia, pleural infection is one of the oldest and severest diseases with an increasing incidence in many countries. $3,7,8$ In according to the literature, $1,3,9,10$ empyema thoracis remain a current pathology in developing countries. In most cases, it follows an attack of bronchopneumonia, but other debilitating conditions such as measles, malnutrition, immunodeficiency, malaria and sickle cell anemia form part of the clinical syndrome. $9,11,12$

The case reported emphasizes the standard medical approach in managing severe childhood empyema particularly where facilities are inadequate, as in DRC. Ultrasound scanning, which is now readily available, is the preferred investigation enabling the exact location of any fluid collection and guided diagnostic aspiration if required. In the absence of a pediatric respiratory unit and thoracic surgeon without echograph and fibrinolytics in our district in compliance to the guideline, we opted for conservative management (antibiotics + simple drainage) and the evolution was good.

There is very little data on prevalence, diagnosis approach and its management especially in DRC where facilities, diagnostic instrumentation and bacteriological tools are inadequate. Moreover, in that country, measles, anemia from other causes, malnutrition, malaria, sickle cell disease, and gastroenteritis complicate the clinical progress and management of pleural sepsis. These conditions are no longer prevalent in developed countries, but in developing countries they represent a serious clinical challenge. This is because of the high incidence of respiratory disease and inadequacy of medical facilities.

Empyema is a known complication of pneumonia yet the frequency of this complication is not well documented in developing countries. Earlier reports $1,6,9$ have suggested a rate of less than $1 \%$ while there have been other studies reporting an occurrence of parapneumonic effusions of up to $12 \%$. Causes for the increase in incidence remain uncertain, but the use of a wide range of pneumococcal vaccines in children and an increasingly aging global society, with an increase of elderly chronic diseases, have been forwarded. 11,13

In children, the most common microorganism that causes empyema continues to be Streptococcus pneumoniae. Interestingly, the widespread use of seven valent conjugate vaccines has produced are placement phenomenon with the emergence of some pneumococcal serotypes such as serotypes 1,3 and 19A, which have a higher propensity to cause empyema. Moreover increases in the incidence of empyema due to Staphylococcus aureus have also been observed. 3,8

In view of the substantial mortality associated with pleural infection, it is appropriate to focus the care of this disorder in specialist hands. Early diagnosis and proper treatment of pneumonia prevents the development of empyema. The process of rapid evaluation and therapeutic intervention appears to reduce morbidity and mortality, as well as healthcare costs. $6,14,15$ Delay to chest tube drainage of the pleural space is probably associated with increased morbidity and duration of hospital stay, and may lead to increased mortality.4,13,15 Misdiagnosis, inappropriate antibiotics, and delay in referral to hospital are probably important factors contributing to the progression of pleural infection. ${ }^{1}$ Enlarged empyema is a significant cause of morbidity and mortality in children often if not

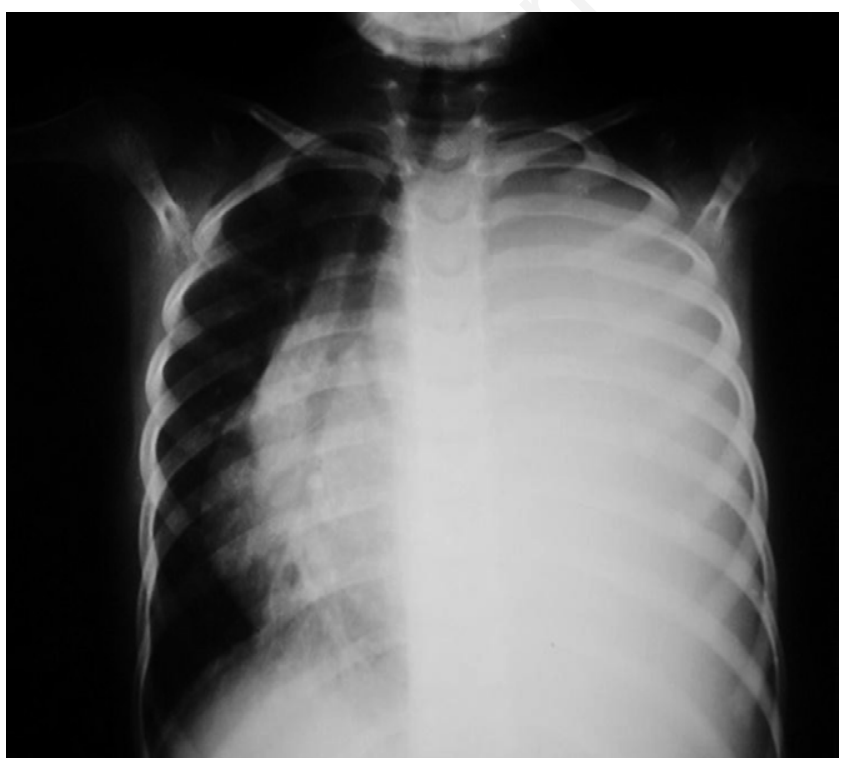

Figure 1. Chest $\mathrm{X}$-ray performed at the admission.

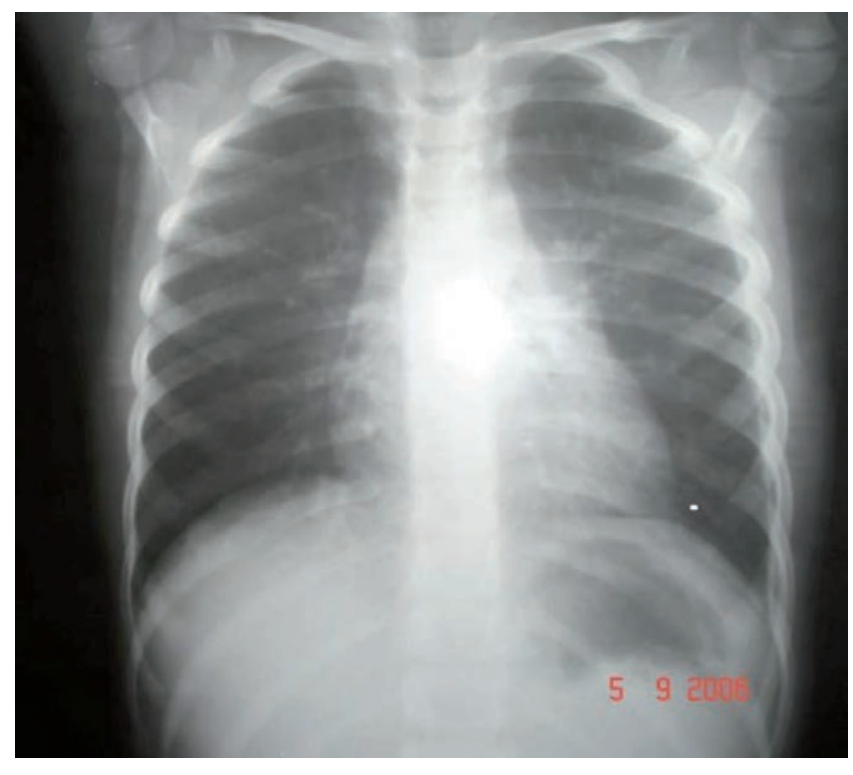

Figure 2. Chest X-ray 3 months later (follow up). 
seen at an early stage by a trained physician as occurs generally in low income countries and at times presents a therapeutic challenge. There is great variation world wide in the management of patients with pleural infection, and approaches differ between physicians especially in developing countries due to the absence of facilities. ${ }^{15-17}$ Since the mid 1990s, management strategies using fibrinolytics (introduced first in 1949) and thoracoscopic surgery have evolved. Although the British Thoracic Society published national guidelines in 2005 for the management of pleural infection in children, the treatment of choice remains a matter of controversy in the literature and in clinical practice. Surgical treatment by thoracentesis (needle or tube) for severe empyema is a simple and effective procedure that may be performed by most doctors in hospitals lacking thoracic surgeons. It can be life-saving in a severely distressed child.

\section{Conclusions}

In conclusion, in this case report an urgent closed chest drainage of empyema thoracis combined with antibiotics, using a classic medical and imaging approach which seems to be a great challenge in low income countries, allows a good evolution according to the BTS. ${ }^{6}$ Follow up studies have shown that, despite the heterogeneity of treatment approaches, the majority of children make a complete recovery and their lung function returns to normal. 4,5

\section{References}

1. Hailu S. Paediatric thoracic empyema in an Ethiopian referral hospital. East Afr Med J 2000;77:618-21.

2. Chan W, Keyser-Gauvin E, Davis GM et al. Empyema thoracis in children: a 26-year review of the Montreal Children's Hospital experience. J Pediatr Surg 1997;32:870-2.
3. Zampoli M, Kappos A, Wolter N, et al. Etiology and incidence of pleural in South African children. Pediatr Infect Dis J 2015;34:1305-10.

4. Kwon YS. Pleural Infection and empyema. Tuberc Respir Dis 2014;76:160-2.

5. Sonnappa S, Jaffe A. Treatment approaches for empyema in children. Paediatr Respir Rev 2007;8:164-70.

6. Balfour-Lynn IM, Abrahamson E, Cohen G, et al. BTS guidelines for the management of pleural infection in children. Thorax 2005;60(Suppl.1):1-21.

7. Brims FJ, Lansley SM, Waterer GW, Lee YCG. Empyema thoracis: new insights into an old disease. Eur Respir Rev 2010;19:220-8.

8. Burgos J, Falco V, Pahissa A. The increasing incidence of empyema. Curr Opin Pulm Med 2013;19:350-6.

9. Anyanwu CH, Egbue M. Management of pleural sepsis in Nigerian children. Thorax 1981;36:282-5.

10. Cham CW, Haq SM, Rahamim J. Empyema thoracis: a problem with late referral? Thorax 1993;48:925-27.

11. Fletcher MA, Schmitt HJ, Syrochkina M, Sylvester G. Pneumococcal empyema and complicated pneumonias: global trends in incidence, prevalence, and serotype epidemiology. Eur J Clin Microbiol Infect Dis 2014;33:879-910.

12. Taylor WR, Hanson J, Turner GD, et al. Respiratory manisfestations of malaria. Chest 2012;142:492-505.

13. Walker W, Wheeler R, Legg J. Update on the causes, investigation and management of empyema in childhood. Arch Dis Child 2011;96:482-8.

14. Sommerburg O, Schenk JP, Mall MA. Lung diseases in children. Radiologe 2015;55:545-53.

15. Parsons SJ, Fenton E, Williams M. Paediatric empyema: a case report and literature review. Crit Care Resusc 2005;7:102-6.

16. Zampoli M, Kappos A, Verwey C, et al. Impact of fibrinolytics on the outcome of empyema in South African Children. S Afr Med J 2015;105:549-53.

17. Hafen GM, Grenzbach AC, Moeller A, Rochat MK. Lack of concordance in parapneumonic effusion management in children in central Europe. Pediatr Pulmonol 2016;51:411-7. 